\title{
The REC2 Gene Encodes the Homologous Pairing Protein of Ustilago maydis
}

\author{
ERIC B. KMIEC, ${ }^{1}$ ALLYSON COLE, ${ }^{1}$ AND WILLIAM K. HOLLOMAN ${ }^{2 *}$ \\ Department of Pharmacology, Jefferson Cancer Center, Thomas Jefferson University, Philadelphia, \\ Pennsylvania 19117, ${ }^{1}$ and Department of Microbiology, Cornell University Medical College,
} New York, New York $10021^{2}$

Received 2 June 1994/Returned for modification 29 June 1994/Accepted 28 July 1994

\begin{abstract}
Amino acid sequence analysis has established that the homologous pairing protein of Ustilago maydis, known previously in the literature as rec1, is encoded by $R E C 2$, a gene essential for recombinational repair and meiosis with regional homology to Escherichia coli RecA. The 70-kDa rec1 protein is most likely a proteolytic degradation product of REC2, which has a predicted mass of $84 \mathrm{kDa}$ but which runs anomalously during sodium dodecyl sulfate-gel electrophoresis with an apparent mass of $110 \mathrm{kDa}$. To facilitate purification of the protein product, the $R E C 2$ gene was overexpressed from a vector that fused a hexahistidine leader sequence onto the amino terminus, enabling isolation of the REC2 protein on an immobilized metal affinity column. The purified protein exhibits ATP-dependent DNA renaturation and DNA-dependent ATPase activities, which were reactions characteristic of the protein as purified from cell extracts of $U$. maydis. Homologous pairing activity was established in an assay that measures recognition via non-Watson-Crick bonds between identical DNA strands. A size threshold of about 50 bp was found to govern pairing between linear duplex molecules and homologous single-stranded circles. Joint molecule formation with duplex DNA well under the size threshold was efficiently catalyzed when one strand of the duplex was composed of RNA. Linear duplex molecules with hairpin caps also formed joint molecules when as few as three RNA residues were present.
\end{abstract}

Genetic recombination can be envisioned as a pathway that proceeds stepwise through a search for sequence homology, DNA pairing, heteroduplex formation, and exchange of strands. Elucidation of the process has come in part from detailed analysis of Escherichia coli RecA protein. Studies on the biochemical mechanism have revealed the protein to catalyze homologous pairing of DNA molecules in a reaction that transduces the energy of nucleotide cofactor binding to changing conformational states of the protein and to promote strand exchange by coupling nucleotide hydrolysis to unidirectional processing of the crossed-strand recombination intermediate $(22,24,25,28,38)$. The RecA protein has become the paradigm for thinking about the mechanism of DNA pairing in general homologous recombination. The ubiquity of RecA in bacteria has reinforced the hope that lessons learned from studies of this prototype system may be extended beyond the realm of prokaryotes.

Evidence supporting the notion that eukaryotes might conduct recombination through a RecA-like DNA pairing mechanism has come from two approaches. Genetic studies led to the discovery, first made in Saccharomyces cerevisiae $(1,2,5$, $14,30)$ and later in other eukaryotes, of proteins homologous to RecA (for a review, see reference 11). On the other hand, biochemical studies with Ustilago maydis revealed the presence of an activity that could promote a number of DNA pairing reactions, some of which resembled reactions catalyzed by RecA protein (15). These included ATP-stimulated reassociation of complementary single strands, uptake by a superhelical DNA molecule of a third homologous single-stranded fragment, and transfer of a single-stranded circular DNA molecule onto a homologous linear duplex molecule. The homologous

\footnotetext{
${ }^{*}$ Corresponding author. Mailing address: Department of Microbiology, Cornell University Medical College, 1300 York Ave., New York, NY 10021. Phone: (212) 746-6510. Fax: (212) 746-8587.
}

pairing activity was subsequently discovered associated with a DNA-dependent ATPase activity. Homologous pairing was not blocked by topological barriers that would preclude true heteroduplex formation and strand intertwining. Pairing proceeded between a single-stranded circle and homologous superhelical DNA (21) or with single-stranded circular molecules and linear duplexes containing homologous sequences flanked by long stretches of heterology (17). Pairing activity was also observed between two duplex circles under conditions in which there was either active transcription, a previously formed D loop, or else the presence of DNA sequences with the potential to flip to the Z-DNA form $(18,21)$. Studies reporting purification of strand exchange activities from a variety of other eukaryotic sources have also been made, but with the exception of the activity from $U$. maydis, there has been no documented example of an ATP-dependent activity (for a review, see reference 23 ).

The $U$. maydis homologous pairing activity was attributed to a 70-kDa polypeptide that was enriched during purification using ATP-stimulated reannealing of complementary single strands as an assay. The $70-\mathrm{kDa}$ protein was named rec1 since it was the first protein purified from $U$. maydis with at least some of the hallmarks of RecA-like pairing activities. This naming was also prompted by the finding of an absence of detectable reannealing activity in the expected chromatographic cut after fractionating extracts from the rec1 mutant, which raised the possibility of a direct connection between the gene altered in the recl mutant and the rec1 protein (16). However, without a molecular cloning and gene transfer system in $U$. maydis, it was not possible at that time to draw a definitive conclusion regarding the identity of the structural gene of the rec1 protein.

Over the past several years, efforts have been devoted to developing a method for isolating the structural gene from in $U$. maydis. In this paper, we report the identification of the gene encoding the rec1 protein. It is $R E C 2$, a gene previously 
isolated in a study on the DNA repair and recombination deficiency of the rec2 mutant (3). REC2 is responsible for recombinational repair following DNA damage, gene targeting between plasmid DNA and homologous sequences in the genome during transformation, and successful meiosis $(9,12$, 29). Here we report some properties of the homologous pairing protein after overexpression of the cloned gene.

To avoid confusion, we propose the following nomenclature. The $R E C 1$ and $R E C 2$ genes should be indicated with capitalized italics, and the corresponding mutants should be indicated with lowercase italics. The product of the $R E C 2$ gene should be referred to in roman type with capitalization as REC2 or Rec2 protein. Similarly, the product of the $R E C 1$ gene should be referred to as REC1 or Rec1 protein. The 70-kDa homologous pairing protein, which is a truncated form of the REC2 protein but has been known previously in the literature as rec1, should be referred to as $\mathrm{REC} 2^{\mathrm{p} 70}$ or $\operatorname{Rec} 2^{\mathrm{p} 70}$.

\section{MATERIALS AND METHODS}

Plasmids and strains. A 2.8-kbp U. maydis DNA fragment modified by site-directed mutagenesis to contain an NdeI site at the putative translational initiation codon was inserted into pET3b (Novagen, Inc., Madison, Wis.) to yield pCM361. This construction places the $R E C 2$ open reading frame under control of the bacteriophage T7 $\phi 10$ gene promoter. Similarly, a 2.5 -kbp DNA fragment containing the $R E C 2$ open reading frame engineered with the NdeI site at the initiation methionine codon was inserted at the NdeI site of pET14b to yield pCM349. pCM525 is pET3b containing a fragment encoding the last 96 amino acid residues of REC2 inserted into the BamHI site of pET3b. Expression of this construct results in generation of a fusion protein of $12 \mathrm{kDa}(\phi 10:: \Delta R E C 2)$ composed of 12 amino acid residues of the $\mathrm{T} 7 \phi 10$ protein and the 96 amino acid residues of REC2. E. coli BCM464 is $E$. coli BL21(DE3) ( $\mathrm{F}^{-}$hsdS gal/Aint::lacUV5-T7 gene $1 \mathrm{imm}^{21}$ nin5 Sam7) (32) transformed with pCM361. E. coli JCC100 is

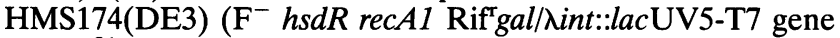
1 imm $^{21}$ nin5 Sam7) (6) harboring plasmid pLysS (31) and transformed with pCM349. E. coli BCM700 is BL21(DE3)/ pLysS transformed with pCM525.

Amino acid sequences of peptides. Peptide sequences were obtained from two different preparations of protein. In the first, approximately $50 \mathrm{pmol}$ of rec1 protein in solution, purified by the method of Kmiec and Holloman (19), was digested with trypsin. Peptides generated were separated by narrow-bore reverse-phase high-pressure liquid chromatography (HPLC). Peptides were sequenced on an Applied Biosystems 477A sequencer with an on-line detector for phenylthiohydantoin-derived amino acids. The following sequences were obtained in order of elution from HPLC: trp 1, DAVAAAD; $\operatorname{trp} 2, \mathrm{FVFD}(\mathrm{S} / \mathrm{A}) \mathrm{A}(\mathrm{H} / \mathrm{G}) \mathrm{R} ; \operatorname{trp} 3, \mathrm{SI}(\mathrm{V} / \mathrm{M}) \mathrm{N} / \mathrm{DRA} ; \operatorname{trp} 4$, $(\mathrm{V} / \mathrm{G})(\mathrm{F} / \mathrm{Y}) \mathrm{LSKTR}(\mathrm{A} / \mathrm{T}) \mathrm{RIC}(\mathrm{M} / \mathrm{G}) \mathrm{R}$; and trp 5, S(?/T)(V/ $\mathrm{M}) \mathrm{MH}(\mathrm{A} / \mathrm{D}) \mathrm{MHA}$. The virgule indicates ambiguity in identification. From a second preparation of protein, a comparable fraction was electrophoresed under denaturing conditions in a $10 \%$ polyacrylamide gel containing sodium dodecyl sulfate (SDS) and then electrophoretically transferred onto a nitrocellulose membrane. A 70-kDa protein band which appeared after staining with Ponceau $S$ to be composed of a tightrunning doublet was located and excised from the nitrocellulose membrane with a razor. The strip was cut in two to separate the doublet members, and sequence determination was carried out individually. These determinations yielded the following sequences: N-term 1, FASSCIVP; and N-term 2, YDSDAGSDSD. Trypsin digestion, peptide fractionation, and sequencing were carried out at the Harvard microchemistry facility by William S. Lane and Violaine Bailey. Sequencing of the polypeptides blotted on nitrocellulose was carried out at the Jefferson Cancer Center microchemistry facility by Garrett Dubois.

Immunoblot analysis. The 12-kDa $\phi 10:: \triangle \mathrm{REC} 2$ fusion protein was prepared from a $100-\mathrm{ml}$ culture of $E$. coli BCM700 grown to an $A_{590}$ of 0.7 in M9ZB medium (32) plus chloramphenicol $(35 \mu \mathrm{g} / \mathrm{ml})$ and ampicillin $(100 \mu \mathrm{g} / \mathrm{ml})$ and induced with $4 \mathrm{mM}$ isopropyl- $\beta$-D-thiogalactopyranoside (IPTG). After $2 \mathrm{~h}$, cells were harvested and lysed by heating at $100^{\circ} \mathrm{C}$ in $3 \mathrm{ml}$ of $50 \mathrm{mM}$ Tris- $\mathrm{HCl}$ (pH 8.3)-2\% SDS-5\% 2-mercaptoethanol. The total lysate was loaded and electrophoresed in a preparative $15 \%$ polyacrylamide gel. The $12-\mathrm{kDa}$ protein was located after staining of a parallel lane of the gel with Coomassie brilliant blue. It was obtained after excising the acrylamide band containing the protein and eluting the minced gel slice by soaking in $50 \mathrm{mM}$ Tris- $\mathrm{HCl}(\mathrm{pH} \mathrm{7.5)}-150 \mathrm{mM} \mathrm{NaCl}-0.1 \%$ SDS. Approximately $2 \mathrm{mg}$ of protein was obtained by this procedure and used for immunization. Serum from rabbit immunized with the fusion protein (Pocono Rabbit Farm, Canadensis, $\mathrm{Pa}$.) was used at 1:5,000 dilution for Western blot (immunoblot) analysis. Goat anti-rabbit alkaline phosphataseimmunoglobulin $\mathrm{G}$ conjugate was used for detection as described by the manufacturer (Promega Corp., Madison, Wis.).

Overexpression of $\boldsymbol{R E C} 2$ and protein purification. A culture $(500 \mathrm{ml})$ of $E$. coli JCC100 was grown in $2 \times$ YT medium $(8 \mathrm{~g}$ of tryptone, $5 \mathrm{~g}$ of yeast extract, and $5 \mathrm{~g}$ of $\mathrm{NaCl}$ per liter) containing chloramphenicol $(35 \mu \mathrm{g} / \mathrm{ml})$ and ampicillin $(100$ $\mu \mathrm{g} / \mathrm{ml}$ ) at $37^{\circ} \mathrm{C}$. At an $A_{590}$ of 0.6 , IPTG (Sigma Chemical Co.) was added to $1 \mathrm{mM}$. After $2 \mathrm{~h}$, the cells were harvested by centrifugation, washed once in $\mathrm{BB}$ buffer $(20 \mathrm{mM}$ Tris- $\mathrm{HCl}$ [pH 7.9], 0.5 M NaCl, $5 \mathrm{mM}$ imidazole), and then resuspended in $30 \mathrm{ml}$ of BB buffer containing $0.5 \mathrm{mM}$ phenylmethylsulfonyl fluoride. Cells were ruptured by sonication (Branson Sonifier 350) with three bursts of power for $30 \mathrm{~s}$ each, with intermittent cooling in ice water. The broken cell suspension was cleared by centrifugation $(15,000 \mathrm{rpm}$ for $20 \mathrm{~min}$, Sorvall SS34), and the supernatant was discarded. The pellet was resuspended in 10 $\mathrm{ml}$ of $\mathrm{BB}$ buffer containing $6 \mathrm{M}$ guanidine- $\mathrm{HCl}$ and allowed to stand overnight on ice. Insoluble debris was removed by centrifugation, and the supernatant (fraction I) was then loaded onto nitrilotriacetic acid-agarose (Qiagen, Inc., Chatsworth, Calif.), an immobilized metal affinity column, charged with $\mathrm{Ni}^{2+}$ and equilibrated with BB buffer. The column (1.5 $\mathrm{ml}$ ) was washed with $\mathrm{BB}$ buffer and then eluted stepwise with increasing concentrations of imidazole $(60 \mathrm{mM}$ and then 100 $\mathrm{mM})$. REC2 protein eluted with $100 \mathrm{mM}$ imidazole. Fractions $(1 \mathrm{ml})$ were collected, and those containing REC2 protein (5 $\mathrm{ml}$ ) were pooled and dialyzed against TNE buffer $(50 \mathrm{mM}$ Tris- $\mathrm{HCl}$ [pH 8.5], $100 \mathrm{mM} \mathrm{NaCl}, 1 \mathrm{mM}$ EDTA) containing 6 $\mathrm{M}$ urea. After $3 \mathrm{~h}$, the dialysis bag was placed in a small beaker and covered with $10 \mathrm{ml}$ of the same buffer. TNE buffer without urea $(10 \mathrm{ml})$ was then added every $15 \mathrm{~min}$ until the volume was $200 \mathrm{ml}$. Failure to remove denaturant by this slow-dialysis regimen resulted in precipitation of the REC2 protein. This sample (fraction II) was then loaded onto a heparin-agarose column $(1 \mathrm{ml})$ and subsequently washed with $5 \mathrm{ml}$ of TNE buffer. REC2 protein was eluted with TNE buffer plus $0.25 \mathrm{M}$ $\mathrm{NaCl}$, and fractions of $0.5 \mathrm{ml}$ were collected. REC2 eluted at tubes 7 to 9 . The pooled peak was dialyzed against TNE buffer containing $10 \%$ glycerol, aliquoted, and stored frozen at $-70^{\circ} \mathrm{C}$. The molar extinction coefficient calculated for REC2 protein at $280 \mathrm{~nm}$ was $3.16 \times 10^{4} \mathrm{M}^{-1} \mathrm{~cm}^{-1}$.

Nucleic acid substrates. Oligonucleotides (Table 1) were synthesized on an Applied Biosystems 394 nucleic acid synthe- 
TABLE 1. Oligonucleotides used

\begin{tabular}{|c|c|}
\hline Oligonucleotide & Sequence $^{a}$ \\
\hline \multirow{2}{*}{\multicolumn{2}{|c|}{...'TAGAGGATCCCCGGGTTTTCCCGGGGATCCTCTAGAGTTTTCTC3' }} \\
\hline & ...5'TAGAGGATCCCCGGGTTTTCCCGGGGATCCTCTAGAGTTTTCTC3' \\
\hline \multicolumn{2}{|r|}{...5'TAGAGGATCCCCGGGTTTCCCGGGGAUCCUCUAGAGTTT } \\
\hline \multicolumn{2}{|r|}{ 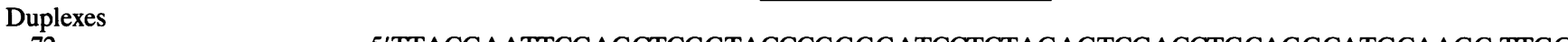 } \\
\hline \multirow[t]{4}{*}{ 72-mer ... } & ...5'TTACGAATTCGAGCTCGGTACCCGGGGATCCTCTAGAGTCGACCTGCAGGCATGCAAGC TTGG \\
\hline & CACTGGCCG3' \\
\hline & 3'AATGCTTAAGCTCGAGCCATGGGCCCCTAGGAGATCTCAGCTGGACGTCCGTACGTT \\
\hline & GTGACCGGC5' \\
\hline \multicolumn{2}{|c|}{ 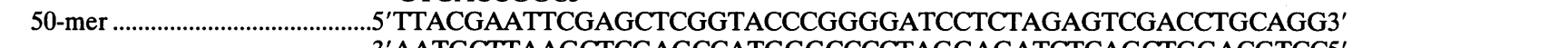 } \\
\hline & 3'AATGCTTAAGCTCGAGCCATGGGCCCCTAGGAGATCTCAGCTGGACGTCC5' \\
\hline \multicolumn{2}{|c|}{ 30-mer ……............................'TTACGAATTCGGCTCGGTACCCGGGGATC3' } \\
\hline & 3'AATGCTTAAGCTCGAGCCATGGGCCCCTAG5' \\
\hline RNA 30-mer.......... & ....3'AAUGCUUAAGCUCGAGCCAUGGGCCCCUAG5' \\
\hline
\end{tabular}

${ }^{a}$ RNA sequences are underlined.

sizer and purified by capillary electrophoresis. Concentrations were determined spectrophotometrically as total nucleotide, using an $\varepsilon_{260}$ of $8.3 \times 10^{3} \mathrm{M}^{-1} \mathrm{~cm}^{-1}$. Oligonucleotides were labeled with ${ }^{32} \mathrm{P}$ by using polynucleotide kinase and $\left[\gamma^{-}{ }^{32} \mathrm{P}\right]$ ATP as described by van de Sande et al. (35). Specific activities of oligonucleotides were $1.5 \times 10^{3}$ to $2.5 \times 10^{3}$ $\mathrm{cpm} / \mathrm{fmol}$ (as molecules). Hybrid duplexes were prepared by annealing the appropriate complementary oligonucleotides in stoichiometric amounts at $65^{\circ} \mathrm{C}$ in $0.4 \mathrm{M} \mathrm{NaCl}$ for $15 \mathrm{~min}$ and then purified and freed of any excess single-stranded oligonucleotide by electrophoresis in a D600 gel (AT Biochem, Malvern, Pa.). The duplex oligonucleotide was excised in a band from the gel, electroeluted, and concentrated after precipitation with ethanol.

Reactions. Joint molecule formation was measured by a filter retention assay in which complexes composed of singlestranded and duplex DNA molecules were trapped on nitrocellulose filters. The assay was developed by Bianchi et al. (4) to measure metastable intermediates that may not survive removal of protein. Samples $(20 \mu \mathrm{l})$ were withdrawn into $1 \mathrm{ml}$ of $10 \times \mathrm{SSC}$ (SSC is $0.15 \mathrm{M} \mathrm{NaCl}$ plus $0.015 \mathrm{M}$ sodium citrate [pH 7.8]) without deproteinization, and the mixture was passed onto a nitrocellulose filter (BA85; $0.45-\mu \mathrm{m}$ pore size; Schleicher \& Schuell, Keene, N.H.) that had been soaked extensively in water and then rinsed in $10 \times$ SSC. Filters were washed twice with $1 \mathrm{ml}$ of $10 \times \mathrm{SSC}$ and then dried under a heat lamp, and the bound radioactive DNA was quantitated by scintillation counting in Econofluor (Dupont NEN).

Identical strand pairing reactions were carried out essentially as described by Rao and Radding (26) except that the carrier DNA used was poly(dA-dT) rather than heterologous single-stranded oligonucleotide. Reaction mixtures contained M13 single-stranded circular DNA and ${ }^{32} \mathrm{P}$-labeled oligonucleotide. The identical strand oligonucleotide was a $33-\operatorname{mer}\left(5^{\prime} \mathrm{A}\right.$ CAGCACCAGATTCAGCAATTAAGCTCTAAGCC3') which corresponds to residues 207 to 239 of M13 DNA (36). Control reactions measuring hybrid DNA formation between complementary antiparallel sequences were performed with M13mp18 DNA and a ${ }^{32}$ P-labeled 44-mer (5'GAATTCGAGC TCGGTACCCGGGGATCCTCTAGAGTCGACCTGCA3') which corresponds to residues 412 to 455 of M13mp18 DNA.

Renaturation reactions were carried out by monitoring the increase in resistance of denatured P22 $\left[{ }^{3} \mathrm{H}\right]$ DNA to digestion by $S 1$ nuclease as described before (19). ATPase activity was measured in reaction mixtures $(50 \mu \mathrm{l})$ containing $25 \mathrm{mM}$ Tris- $\mathrm{HCl}$ (pH 7.5), $10 \mathrm{mM} \mathrm{MgCl}, 1 \mathrm{mM}$ dithiothreitol, $20 \mu \mathrm{M}$ M13 DNA, and $0.5 \mathrm{mM}\left[\gamma^{32}\right.$ P]ATP at $10^{5} \mathrm{cpm} / \mathrm{nmol}$. Reac- tions were started by addition of REC2 protein, conducted at $37^{\circ} \mathrm{C}$, and quenched by addition of $100 \mu \mathrm{l}$ of $10 \mathrm{mM}$ potassium phosphate, $100 \mu$ l of acetone, $50 \mu$ l of ammonium molybdate in $4 \mathrm{~N} \mathrm{H}_{2} \mathrm{SO}_{4}$, and $700 \mu$ l of isobutanol-benzene (1:1). After the mixture was vortexed and the phases were separated, half $(350 \mu \mathrm{l})$ of the organic phase (top) was removed and the radioactivity was determined by Cerenkov counting.

Nucleotide sequence accession number. The GenBank accession number for the sequence presented is L18882.

\section{RESULTS}

Identification of $\mathrm{REC} 2$ as the gene encoding the rec1 protein. An improvement in the purification procedure (19) enabled isolation of enough of the $70-\mathrm{kDa}$ homologous pairing protein, known previously as rec1, for partial amino acid sequence determination. Two independently prepared protein samples were analyzed. In the first, a pool containing the purest fraction obtained after the final chromatography step in the purification, which appeared to be composed of $>80 \%$ of the 70-kDa polypeptide as judged by SDS-polyacrylamide gel analysis (19), was digested with trypsin, and the resulting proteolytic products were fractionated by reverse-phase HPLC. Five distinct and well-resolved peptides were chosen for further analysis, and partial amino acid sequence was obtained from each through automated sequencing. In the second preparation, the $70-\mathrm{kDa}$ protein appeared as a tightrunning doublet after SDS-gel analysis. Protein was transferred to nitrocellulose membrane, and the two members of the doublet were isolated by excising them in separate nitrocellulose strips. $\mathrm{N}$-terminal sequence was obtained from both of these samples. These two sequences plus the other five sequences obtained from the tryptic peptides were found to correspond precisely to the translated sequence of the $R E C 2$ gene, a gene previously isolated (3) and determined to encode a predicted $84-\mathrm{kDa}$ protein (29) with regional homology to $E$. coli RecA protein (Fig. 1). Since the $\mathrm{N}$-terminal sequences obtained from the $70-\mathrm{kDa}$ doublet members reside within the open reading frame downstream from the presumed initiation codon of the $R E C 2$ gene, it is apparent that the $70-\mathrm{kDa}$ homologous pairing protein is a fragment of the full-length REC2 polypeptide and will be referred to as REC2 ${ }^{\text {p70 }}$. The fragment is missing 130 to $150 \mathrm{~N}$-terminal residues, but the region of homology to RecA remains intact. A likely explanation for the origin of the REC $2^{\mathrm{p} 70}$ protein is that it arises as a proteolytic product of the larger REC2 protein during the course of purification. Proteolytic degradation resulting in 
1 MTGIAIADVGCISKRIKACCRRAKLFSTDEIIL S P P

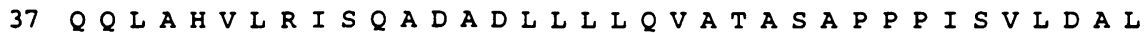

$73 N G K L P A T N L D Q N F F$ DAVAAADDDDDDNDDDDDKA D $S$ txpl

109 G SA D A S T S D A D Q H L N D R FASSCIVPPT Q G Y G N B-tarm 1

145 F P G A C F V YDSDAGSDSDARS S I D A V M E D I E L P S T N-torm 2

181 F C R P T P Q TH DVARDEH H D Y L C D K V D A S VAR D V

217 L S L GR QR HVESSGSRELDDLLGGGVRSAVITELVGE

253 SGSGKTOMAIOVCTYAALGIV PLSQADDHDKGN T T

289 Q S R T F VRDPIHASTKD D T S DILQSYGMEPSIGSHR

325 G MGA C Y I S G GERA A SIVNRALELASFA I NERF DR $\operatorname{trp} 3$

361 VY P CDPTQSSQDADGRRDALIAKAQQLGRRQALAN

397 L H I A C V A D VEALEHALK Y S L P GLIRRLW S SKRQS G V

433 S REI G V V V V D L P A L Q Q D QAAASDIDSLFQRSKML

469 VEIA DALKRISAVQWRGASDCGS A GRAVLVLNHVS

505 D A F G I D Q I A R R FFDSAHRIRTRR S F AR N D P T T $\operatorname{trp} 2$

541 S QAPTSAFSGGTGSALPDQPLAMDVASQTAFTSGLI

577 A S I P T LAEAVGARELDSACAS N D PLRTLEARTAQ

613 L G Q T W S N L I N V RVFLSKTRARICMRDD QA PACE P V R trp 4

649 Q N T N Q R TASKSLMNTVRKA A V IN P F G TMLDVGV

685 DKSALRQLREVITPRKA VH L L A Y P STVMHAMHATA

$\operatorname{trp} 5$

721 DSTPAPESQQQQRAAERHPAEQEDADQDLFGEALQE

757 H H W I I DEL Q S H T TAR P T S R A A A G

FIG. 1. Amino acid sequence alignments of peptides from the homologous pairing protein and the REC2 gene product. Trypsin digestion, peptide separation, and amino acid sequence determination were performed as described in Materials and Methods. The corresponding sequences in the $R E C 2$ gene are indicated in boldface. Sequences designated trp were from tryptic peptides. Those designated N-term were from $\mathrm{N}$-terminal sequencing of the doublet members migrating at an $M_{\mathrm{r}}$ of 70,000 after SDS-gel electrophoresis. Also presented for orientation (underlined) is the sequence with strong homology to a sequence in RecA protein which spans the ATP binding loop motif (residues 251 to 258 ).

heterogeneity in the protein preparations is probably also responsible for (i) the appearance of tryptic peptide trp 1 , which is positioned upstream of the $\mathrm{N}$-terminal sequences determined for the gel-isolated $70-\mathrm{kDa}$ protein, (ii) the infrequent appearance of arginine and lysine residues immediately preceding the tryptic peptide sequences, and (iii) the two $\mathrm{N}$-terminal sequences that were determined.

Overexpression and purification of REC2 protein. A 2.8-kbp genomic DNA fragment with the REC2 open reading frame engineered to contain an $N d e I$ site at the initiation methionine codon was inserted behind the $\phi 10$ bacteriophage T7 promoter in the $\mathrm{pET}$ vector system, which is designed for overexpression of genes in $E$. coli (32). After induction with IPTG, a protein with a mass of $\simeq 110 \mathrm{kDa}$ accumulated in the cells as determined by SDS-gel electrophoresis (Fig. 2B). In a control in which cells contained the vector without the REC2 gene, no accumulation of the $110-\mathrm{kDa}$ protein was noted. With the use of antiserum obtained from rabbit immunized with a $12-\mathrm{kDa}$ fusion protein containing 96 amino acid residues from the carboxy terminus of the REC2 protein (Fig. 2A), it was determined that the $110-\mathrm{kDa}$ protein cross-reacted (Fig. $2 \mathrm{~B}$ ).
While the bulk of the overexpressed protein was insoluble, a small fraction $(\simeq 5 \%)$ remained soluble even in low-ionicstrength buffer. This soluble $110-\mathrm{kDa}$ protein was purified with the aid of the antiserum as a REC2-specific reagent following chromatography on heparin-agarose and fast protein liquid chromatography separation on a Pharmacia MonoS column. $\mathrm{N}$-terminal amino acid sequence determination of 15 residues confirmed the identity of the $110-\mathrm{kDa}$ protein as REC2. Since the predicted mass of REC2 is only $84 \mathrm{kDa}$, it is concluded that the protein runs anomalously under conditions of SDS-gel electrophoresis.

To enable purification of the protein, a $2.5-\mathrm{kbp}$ DNA fragment containing the $R E C 2$ gene was inserted into pET14b, which was designed for expression of fusion proteins preceded by a hexahistidine leader sequence. Because of the utility of the histidine leader sequence in affinity chromatography, the hexahistidine-REC2 fusion was considered more amenable for biochemical studies. After induction of cells with IPTG, the insoluble fraction containing the bulk of the REC2 protein was collected and dissolved in guanidine- $\mathrm{HCl}$ (fraction I). REC2 protein was then isolated by immobilized metal affinity chro- 


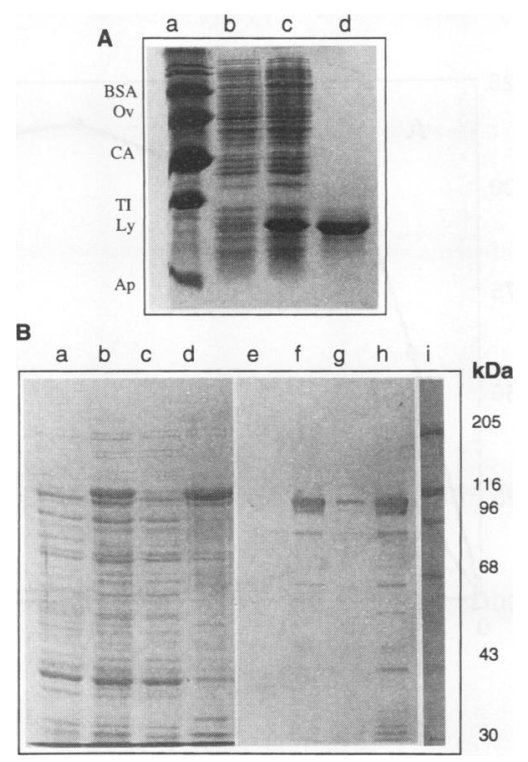

FIG. 2. Overexpression of REC2. (A) SDS-gel analysis of the $\phi 10::$ REC2 fusion protein. E. coli BCM700 carrying plasmid pCM525 was processed as described in Materials and Methods. After harvesting, the cells were lysed by boiling in SDS, and aliquots (5 to $10 \mu \mathrm{g}$ of protein) were electrophoresed on a $15 \%$ polyacrylamide gel which was subsequently stained with Coomassie blue. Lanes: a, molecular weight standards (bovine serum albumin [BSA]), ovalbumin [Ov], carbonic anhydrase [CA], trypsin inhibitor [TI], lysozyme [Ly], and aprotinin [Ap]); b, lysate, uninduced cells; c, induced cells; d, purified $\phi 10:: \triangle R E C 2$ fusion protein. (B) Anomalous mobility of REC2 during SDS-gel electrophoresis. Cultures (10 ml) of $E$. coli 464 in M9ZB were grown to an $A_{590}$ of 0.9 and induced by addition of 4 mM IPTG. After induction, cultures were maintained at $15^{\circ} \mathrm{C}$ and then harvested after $12 \mathrm{~h}$. The cell pellets were frozen in ethanol-dry ice, thawed, and resuspended in $0.9 \mathrm{ml}$ of $50 \mathrm{mM}$ Tris- $\mathrm{HCl}(\mathrm{pH} 7.5)-0.15 \mathrm{M} \mathrm{NaCl}-10$ mM EDTA-1 mM dithiothreitol-10\% glycerol. Lysozyme was added to $0.2 \mathrm{mg} / \mathrm{ml}$, and the suspension was held on ice for $30 \mathrm{~min}$. Triton $\mathrm{X}-100$ was then added to $0.1 \%$. After an additional $30 \mathrm{~min}$ on ice, the samples were centrifuged at $18,000 \times g$ for $30 \mathrm{~min}$. The pellets were solubilized in SDS buffer, and samples were then analyzed by electrophoresis in $10 \%$ polyacrylamide gels (lanes a to d). Protein samples processed in a parallel gel were electrophoretically transferred to nitrocellulose and analyzed by immunoblotting with $\phi 10:: \Delta R E C 2$ fusion protein antiserum (lanes $\mathrm{e}$ to $\mathrm{h}$ ) as described in Materials and Methods. Lanes a and e, uninduced cells, total lysate; lanes $b$ and $f$, induced cells, total lysate; lanes $\mathrm{c}$ and $\mathrm{g}$, soluble fraction from induced cell lysate; lanes $\mathrm{d}$ and $\mathrm{h}$, insoluble fraction from induced cell lysate.

matography (Fig. 3). The denatured protein bound stably to an $\mathrm{Ni}^{2+}$-nitrilotriacetic acid column, while contaminating proteins which lacked the histidine leader were removed by extensive washing. Inclusion of $0.5 \mathrm{M}$ salt in the buffer reduced nonspecific ionic interaction of contaminating proteins. REC2 protein was eluted with an increasing gradient of imidazole and then renatured after exchange of the guanidine- $\mathrm{HCl}$ for urea, followed by gradual stepwise removal of urea. The resulting fraction containing highly purified REC2 protein was completely soluble (fraction II) and was further purified by chromatography on heparin-agarose (fraction III). Protein in the final fraction was composed largely of the $110-\mathrm{kDa}$ REC2 protein (Fig. 3, lane f), although a few other lower-molecularweight proteins were evident upon close inspection. It was considered that these were likely to be proteolytic degradation products, since (i) no such protein bands were evident in similarly processed preparations of extracts made from cells

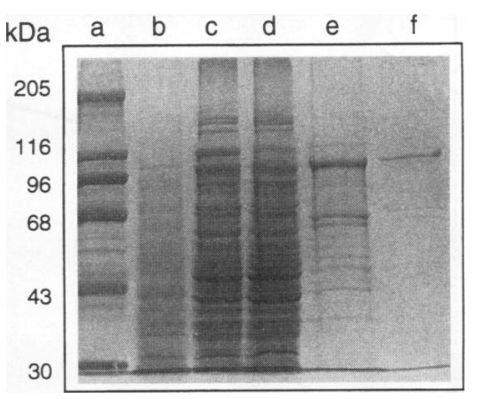

FIG. 3. Purification of REC2 protein. Overexpression and purification of REC2 with a fused hexahistidine leader sequence on the amino terminus was performed as described in Materials and Methods. Samples of protein (1 to $10 \mu \mathrm{g}$ ) were analyzed by SDS-gel electrophoresis in a $7.5 \%$ polyacrylamide gel. The gel was stained with Coomassie blue. Lanes: a, molecular weight markers; $b$, uninduced cell lysate; c, induced cell lysate; d, fraction I; e, fraction II; f, fraction III.

not overexpressing REC2 and (ii) the level of these protein bands increased with a concomitant decrease in the $110-\mathrm{kDa}$ band as a result of prolonged handling of cell extracts in the initial processing (not shown).

The purified REC2 protein promoted ATP-dependent reannealing of complementary single strands of DNA and catalyzed DNA-dependent ATP hydrolysis (Fig. 4), which are reactions that were fundamental in the initial characterization of rec1 protein as purified from cell extracts of $U$. maydis $(15$, 19). The turnover number for the ATP hydrolytic reaction was calculated as $5.3 \mathrm{~min}^{-1}$, which is well below that estimated $\left(225 \mathrm{~min}^{-1}\right)$ in kinetic studies on the $70-\mathrm{kDa}$ protein purified from $U$. maydis cell extracts. One interpretation of these findings is that there is microheterogeneity of the protein preparation due to improper refolding during the renaturation regimen and that only a fraction of the REC 2 protein molecules are active. Another interpretation is that the histidine leader sequence added to the $\mathbf{N}$ terminus of the recombinant protein disturbs the hydrolytic activity. Alternatively, the earlier measurement could have been an overestimation due to uncertainty in protein determinations given the dilute solution of protein available, or else the $70-\mathrm{kDa}$ protein is inherently more active in hydrolyzing ATP than the full-length protein.

Homologous pairing activity. Homologous pairing activity of the REC2 protein was demonstrated by using an assay that is free from interference by reaction leading to heteroduplex formation that can occur through simple second-order renaturation of complementary single strands of DNA (for a review, see reference 20 ). This assay measures identical sequence recognition and was first reported for RecA protein by Rao and Radding (26). An oligonucleotide (33-mer) identical in sequence and polarity to residues 207 to 251 of bacteriophage M13 was synthesized and labeled with ${ }^{32} \mathrm{P}$ at the $5^{\prime}$ end. When this identical-sequence oligonucleotide was present in a reaction at a twofold molar excess over M13 single-stranded circles, REC2 protein promoted formation of a specific complex between the oligonucleotide and M13 DNA that could be trapped on a membrane filter. The complex that formed was completely dependent on ATP (Fig. 5A) and was composed of almost exactly $1 \mathrm{~mol}$ of oligonucleotide per mol of M13 DNA as molecules. No stable complex formed when M13 DNA was replaced by $\phi X 174$ single-stranded circles or when ADP was included in the reaction mixture. The complex was completely dissociated by addition of proteinase $\mathrm{K}$.

In a control reaction using an oligonucleotide complementary and antiparallel to M13 sequence, stable complexes were 

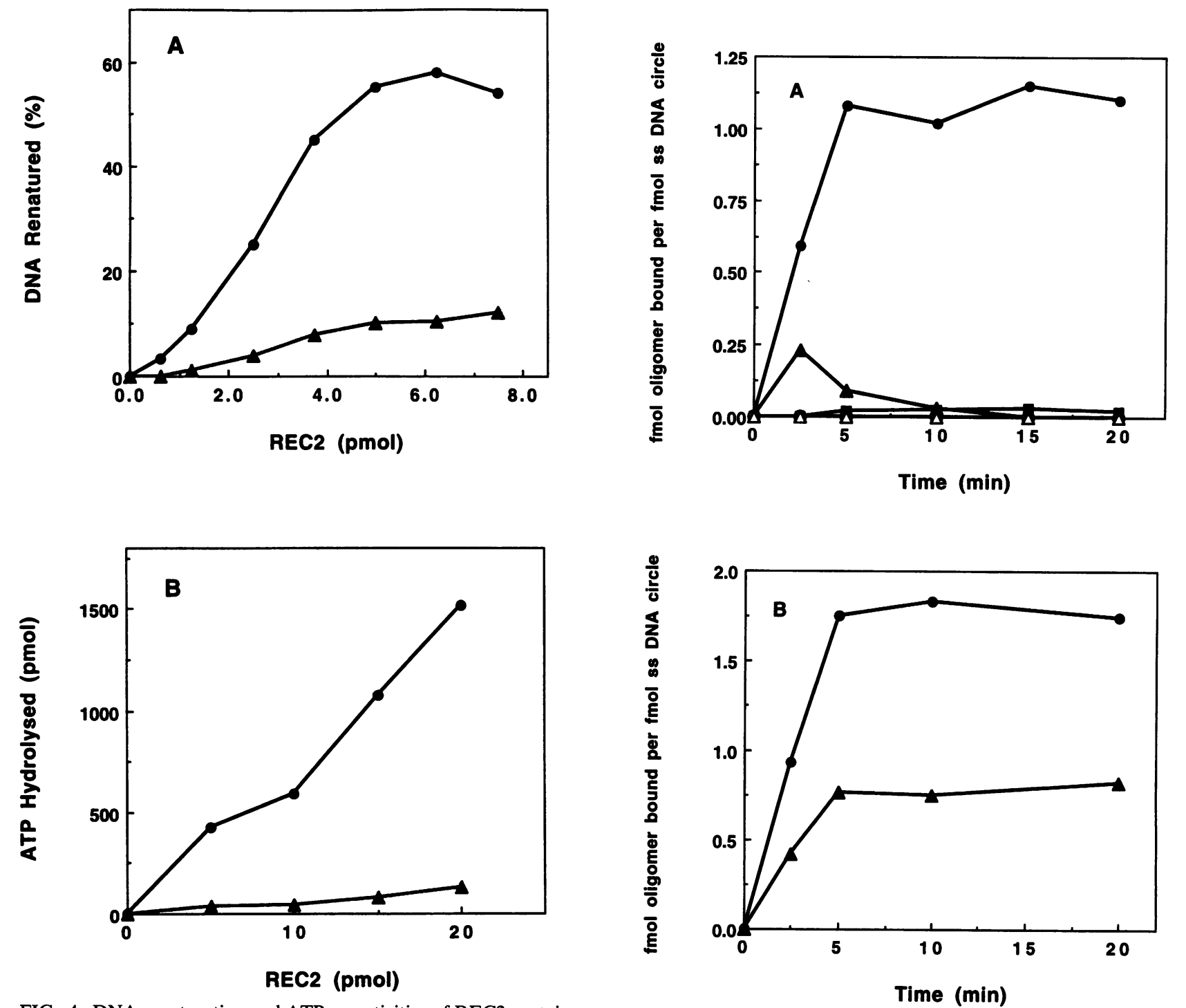

FIG. 4. DNA renaturation and ATPase activities of REC2 protein. (A) Renaturation reactions $(40 \mu \mathrm{l})$ were performed with $20 \mu \mathrm{M}$ denatured P22 [ $\left.{ }^{3} \mathrm{H}\right]$ DNA (as nucleotide) either in the presence of 1 mM ATP (circles) or with no ATP (triangles). Reactions were carried out at $37^{\circ} \mathrm{C}$ for $30 \mathrm{~min}$. DNA renatured indicates the level of input DNA that became resistant to digestion by S1 nuclease. In general, only 80 to $85 \%$ of the DNA could be converted to a form resistant to S1 hydrolysis. The data presented are uncorrected for this value. Protein independent renaturation was $<5 \%$. (B) ATPase reactions were performed as described in Materials and Methods in the presence (dots) or absence (triangles) of $20 \mu \mathrm{M}$ M13 DNA (as nucleotide) at $37^{\circ} \mathrm{C}$ for $15 \mathrm{~min}$.

also formed (Fig. 5B). Interestingly, the stoichiometry of DNAs in the complex was approximately $2 \mathrm{~mol}$ of oligonucleotide per mol of M13 single-stranded circles. After treatment with proteinase $\mathrm{K}$, the ratio dropped to approximately $1: 1$, as would be expected for formation of a heteroduplex joint stabilized through Watson-Crick base pairing.

Activity of RNA-DNA hybrids in joint molecule formation. A series of duplex DNA oligonucleotides of defined lengths was tested for activity in joint molecule formation in a study aimed at exploring the minimum length requirement for homologous pairing by REC2 protein. Joint molecule formation was mon-

FIG. 5. Identical strand pairing. (A) Reaction mixtures $(200 \mu \mathrm{l})$ contained $25 \mathrm{mM}$ Tris acetate (pH 7.5), $10 \mathrm{mM} \mathrm{Mg}^{2+}$ acetate, $1 \mathrm{mM}$ dithiothreitol, $1 \mathrm{mM}$ ATP, $100 \mu \mathrm{g}$ of bovine serum albumin per $\mathrm{ml}, 10$ $\mu \mathrm{M}$ poly(dA-dT) (as nucleotide), $0.41 \mathrm{nM} \mathrm{M} 13$ single-stranded circular DNA (as molecules), and $0.85 \mathrm{nM}{ }^{32} \mathrm{P}$-labeled identical-strand 33-mer oligonucleotide (as molecules). Reactions were initiated by addition of REC2 protein to $0.5 \mu \mathrm{M}$ and incubated at $37^{\circ} \mathrm{C}$, and samples $(20 \mu \mathrm{l})$ were removed. Reactions were then stopped by addition of $200 \mu \mathrm{l}$ of reaction buffer minus DNA, and the mixture was immediately centrifuged through Ultrafree-MC cellulose filters (Millipore) at 2,000 $\times g$ for $6 \mathrm{~min}$ in a tabletop centrifuge. Filters were washed with an additional $100 \mu$ lof buffer and centrifuged for $3 \mathrm{~min}$, and the radioactivity bound was then determined. In the absence of M13 single-stranded DNA, the background of ${ }^{32} \mathrm{P}$ label retained was usually $5 \%$ of the input labeled oligonucleotide. Results are corrected for this background. Closed circles, complete reaction mixture; closed triangles, $\phi$ X174 DNA in place of M13 DNA; closed squares, complete reaction mixture plus $5 \mathrm{mM}$ ADP; open triangles, complete reaction mixture minus ATP; open circles, complete reaction mixture treated with proteinase $\mathrm{K}(100 \mu \mathrm{g} / \mathrm{ml})$ for $10 \mathrm{~min}$. (B) Control reactions using M13mp18 DNA and complementary antiparallel sequence oligonucleotide 44 -mer $(200 \mu \mathrm{l})$ were performed with $0.47 \mathrm{nM}$ M13mp18 DNA and $1.14 \mathrm{nM}{ }^{32} \mathrm{P}$-labeled 44-mer and were processed as described above. Closed circles, complete reaction mixture; closed triangles, complete reaction mixture treated with proteinase $\mathrm{K}$ for $10 \mathrm{~min}$. 
itored in reaction mixtures containing radiolabeled duplex DNA and homologous single-stranded circular M13 DNA. Joint molecules were assayed by measuring retention of labeled DNA on nitrocellulose filters. In reaction mixtures containing a duplex 70-mer, there was efficient joint molecule formation, but when a 50-mer was used, the level dropped markedly (Fig. 6A). No joint molecules could be detected when the duplex was $30 \mathrm{bp}$ in length. Thus, in the case of REC2, there is a minimum length requirement for joint molecule formation that is between five and seven turns of duplex, well above that necessary for stabilizing DNA in the double-stranded conformation (34).

When the 30-mer was composed of an RNA-DNA hybrid, there was considerable joint molecule formation (Fig. 6B). The polarity of the RNA directed the reaction. Complexes were formed when the RNA sequence was complementary to the M13 DNA sequence but not when it was identical.

Activity of hairpin duplexes in joint molecule formation. When the substrates in pairing reactions include. linear duplex molecules and single-stranded circular DNA, interpretation of homologous pairing data can be complicated if the duplex DNA ends are resected by exonuclease digestion. The complementary sequence revealed by this procedure has the potential to hybridize with the circular DNA, leading to formation of joint molecules by a mechanism that circumvents a homologous pairing phase (20). To study the influence of RNA on the homologous pairing aspect of the reaction without the possibility of such complication, a linear duplex substrate with protected ends was devised. This was a linear heteroduplex of RNA and DNA with hairpin caps on both ends (Fig. 7A). It was prepared by synthesis of a single 44-mer oligonucleotide which contained an inverted repeat of complementary sequences. The sequence was designed so that intramolecular association of complementary sequences would result in formation of a linear duplex with hairpin ends. There was a total of $18 \mathrm{bp}$ in the duplex region. Along one strand was a stretch of 18 residues composed entirely of DNA nucleotides. Along the other strand were the 18 complementary residues, 15 of which in contiguous array were RNA nucleotides. At the ends were caps of four residues each of oligo(dT) connecting the complementary strands. The hairpin molecule was labeled at the single open $5^{\prime}$ end with $\left[\gamma^{32} \mathrm{P}\right] \mathrm{ATP}$ and polynucleotide kinase and then sealed with DNA ligase, yielding a covalently closed linear duplex.

Homologous pairing with single-stranded circular DNA as catalyzed by REC2 protein was highly efficient, reaching almost one molecule of hairpin duplex (Fig. 7B) per molecule of single-stranded circular DNA. When the length of the RNA stretch was reduced by systematic replacement of the ribonucleotide residues with deoxyribonucleotide counterparts, the pairing efficiency decreased but did not drop to zero even when only three RNA residues remained (Fig. 8). When all of the nucleotides residues present were deoxyribonucleotides, there was no reaction. Thus, addition of RNA to a duplex can activate it for pairing under conditions in which a completely DNA duplex is inactive. Furthermore, addition of RNA to a duplex brings the minimum homology threshold required for REC2-catalyzed pairing in line with the minimum threshold of length necessary for duplex stability.

\section{DISCUSSION}

The major finding reported in this paper is that the structural gene encoding the homologous pairing protein from $U$. maydis has been identified as $R E C 2$, a gene dedicated to DNA repair and recombination $(9,12)$. This result establishes that it
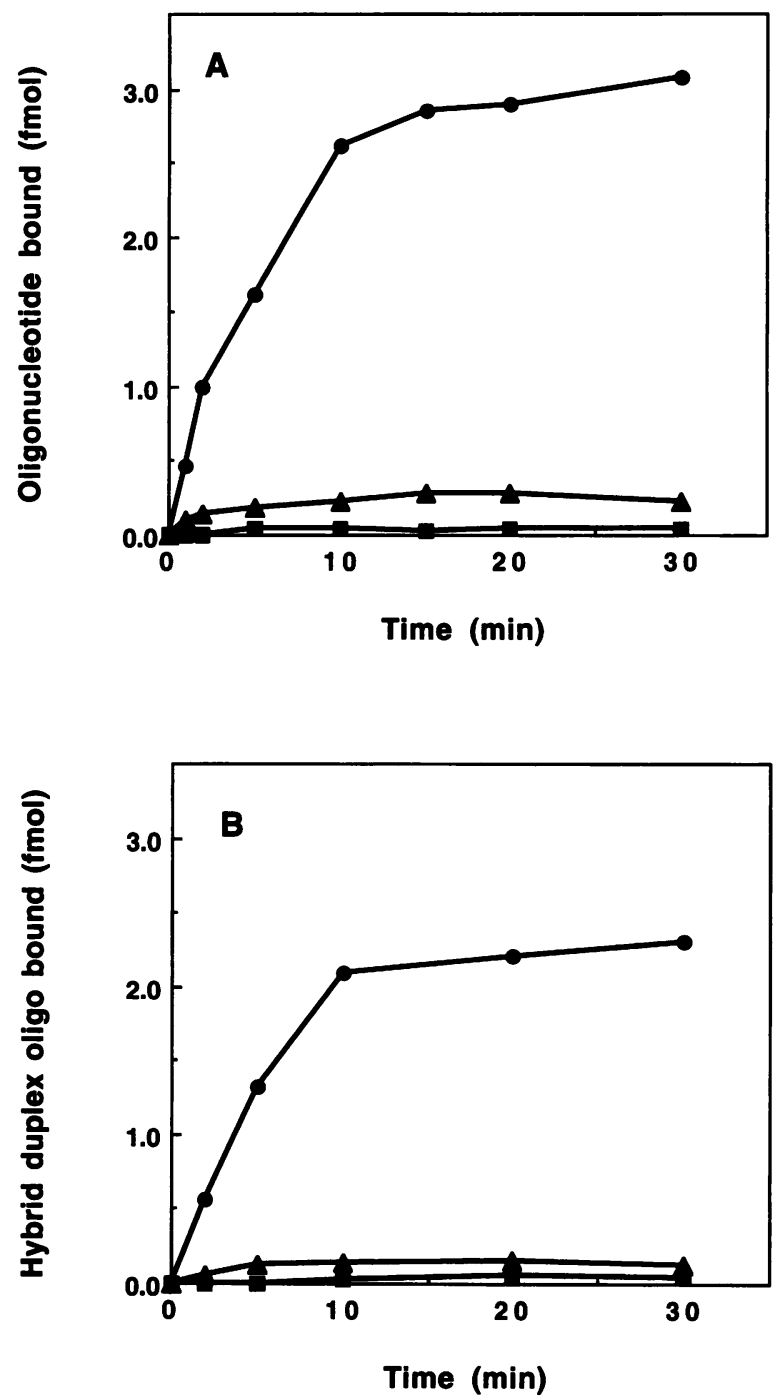

FIG. 6. Threshold length dependence for pairing with DNA-DNA and DNA-RNA hybrids. (A) DNA-DNA hybrids. Duplex fragments were prepared by annealing two complementary ${ }^{32} \mathrm{P}$-labeled oligonucleotides of the indicated lengths and purified by gel electrophoresis as described in the text. The sequences used spanned the multiple cloning site of M13mp19 DNA. Pairing reaction mixtures contained $25 \mathrm{mM}$ Tris- $\mathrm{HCl}$ (pH 7.5), $10 \mathrm{mM} \mathrm{MgCl}, 1 \mathrm{mM}$ ATP, $1 \mathrm{mM}$ dithiothreitol, 0.3 nM M13mp19 single-stranded circular DNA (as molecules), $0.23 \mathrm{nM}$ duplex [ ${ }^{32}$ P]DNA fragment (as molecules), and $0.25 \mu \mathrm{M}$ REC2 protein. At the appropriate time, aliquots were removed and joint molecules were determined. Circles, 72-mer; triangles, 50-mer; squares, 30-mer. (B) RNA-DNA hybrids. 30-mer duplexes that were prepared by hybridizing either complementary sequence DNA oligonucleotides or else complementary RNA and DNA oligonucleotides were tested for pairing. In the latter case, the RNA strand was complementary to the $\mathrm{M} 13 \mathrm{mp} 19$ multiple cloning region. In both cases, only the plus DNA strand oligonucleotides were radiolabeled. Reactions were carried out as described above with M13mp19 singlestranded DNA except where indicated. Circles, DNA-RNA hybrid; squares, DNA-DNA hybird; triangles, RNA-DNA hybrid in reaction with M13mp18 single-stranded DNA.

is indeed possible to isolate authentic recombination functions from cell extracts by using a simple biochemical assay and validates the assumption underlying previous work carried out in this laboratory that pairing activity as measured in vitro was 
A

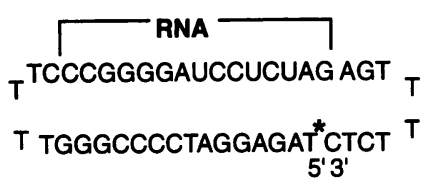

3'_GGGCCCCTAGgaGATCTC - 5'

M13 mp19

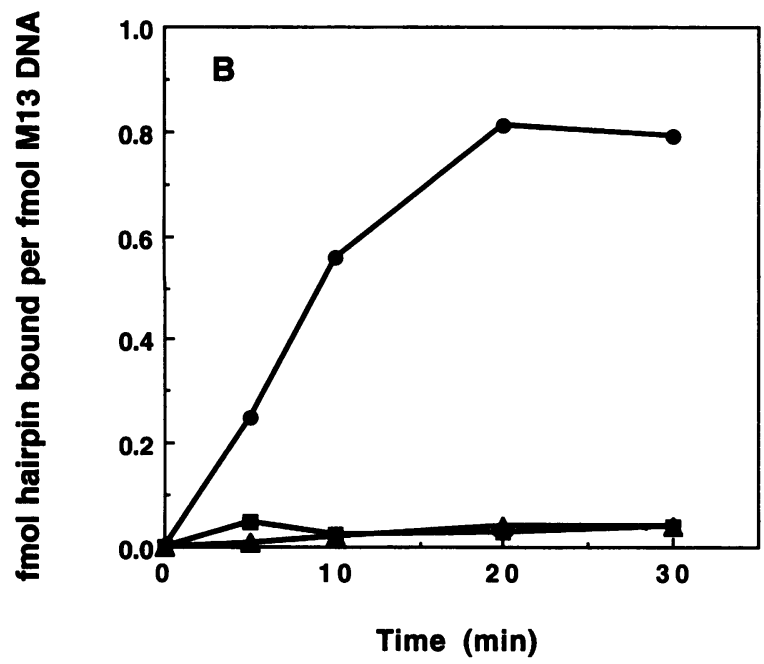

FIG. 7. Joint molecule formation with chimeric hairpin duplex oligonucleotides. (A) Self-complementary DNA or mixed DNA-RNA chimeric oligonucleotide 44-mer sequences were synthesized on an Applied Biosystems 394 DNA-RNA synthesizer. After labeling at the open $5^{\prime}-\mathrm{OH}$ with $\left[\gamma^{-32} \mathrm{P}\right] \mathrm{ATP}$ and polynucleotide kinase, the hairpin was sealed with DNA ligase to generate the form shown schematically. (B) Homologous pairing with an RNA-DNA oligonucleotide hairpin. Joint molecule formation was performed as described in Materials and Methods in reaction mixtures containing $25 \mathrm{mM}$ Tris- $\mathrm{HCl}$ ( $\mathrm{pH} 7.5$ ), 10 $\mathrm{mM} \mathrm{MgCl}, 1 \mathrm{mM}$ ATP, $1 \mathrm{mM}$ dithiothreitol, $0.45 \mathrm{nM} \mathrm{M} 13 \mathrm{mp} 18$ or M13mp19 DNA (as molecules), $1.1 \mathrm{nM}{ }^{32} \mathrm{P}$-labeled oligonucleotide, and $0.5 \mu \mathrm{M}$ REC2 protein. Aliquots $(20 \mu \mathrm{l})$ were removed to $1 \mathrm{ml}$ of $10 \times$ SSC, and joint molecule formation was measured after washing onto nitrocellulose filters. Circles, RNA-DNA chimeric hairpin with M13mp19 DNA; triangles, RNA-DNA chimeric hairpin with M13mp18 DNA; squares, DNA hairpin with M13mp19 DNA.

likely to reflect a biologically significant reaction. The 70-kDa truncated form of REC2, which was referred to previously in the literature as rec1 protein, was the first example of an activity purified from a eukaryote that could promote homologous pairing of DNA molecules. Biochemical analysis of the protein as purified from cell extracts of $U$. maydis revealed functional similarities to $E$. coli $\operatorname{Rec} A$ protein. Notable among these properties were the ATP cofactor requirement for pairing reactions, activity in pairing DNA molecules through regions of homology without regard for DNA ends, and the associated DNA-dependent ATPase. Analysis of the deduced REC2 protein sequence has revealed the presence of a region with strong sequence homology to RecA protein that spans the nucleoside triphosphate binding loop. This region was shown through site-directed mutagenesis to contain residues essential for REC2 function (29). Thus, there are structural as well as functional similarities between REC 2 and RecA protein.

REC2 encodes a protein of 781 amino acids with a calcu-

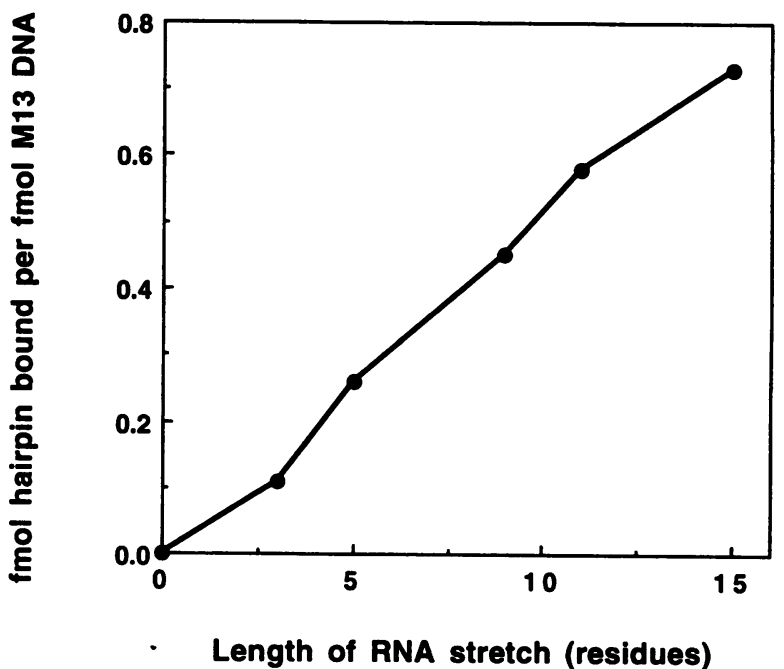

FIG. 8. Contribution of RNA to homologous pairing of chimeric hairpin duplexes. Hairpin-forming chimeric RNA-DNA oligonucleotide 44-mers were synthesized such that the RNA length was progressively reduced by replacement with DNA residues. Replacement proceeded in steps of two starting with the RNA residues proximal to the $3^{\prime}$ terminus. The total base-pair-forming length along both strands was kept at 18 residues. Reactions were carried out as described in the legend to Fig. 6, and chimeric RNA-DNA hairpins bound were assayed after $20 \mathrm{~min}$.

lated mass of $83,935 \mathrm{Da}$. This stands in contrast to RecA protein and the numerous RecA homologs identified in $S$. cerevisiae and other organisms, which are about half the size (for a review, see reference 11). REC2 is also quite different from the known RecA homologs in the extent of homology with RecA. The region of shared sequence homology is over only an internal amino acid stretch of 47 residues. Outside of this region, sequence similarity falls off rapidly. Given this limited sequence, it is arguable whether REC2 might be legitimately categorized as a member of the RecA family. It is not yet known if genes homologous to RecA over their entire lengths are present in $U$. maydis, but it is clear from the phenotype of the rec 2 mutant that REC 2 serves an important role in recombination and repair. This is exemplified in the mutant by the extreme sensitivity to UV light as well as ionizing radiation and alkylating chemicals, the defect in radiationinduced allelic recombination, the decrease in mitotic crossing over, and the failure to complete meiosis (12). The deficiency in targeted recombination observed during DNA-mediated transformation marks the first example in eukaryotes of demonstration of a gene with RecA-like pairing function governing homologous recombination of plasmid and chromosomal sequences (29). It would be interesting to learn whether homologs of REC2 exist in other eukaryotes and if these proteins control recombination during transformation.

Activity of REC2 in pairing single strands of DNA of identical polarity and sequence underscores a fundamental aspect in reaction mechanism shared in common with RecA protein which was first reported as capable of recognizing multiple forms of the same sequence (26). This reaction was of particular interest since it is a true measure of homologous pairing and is not subject to interference or complication from simple hybridization of complementary sequences. The formation of complexes between DNA strands of identical sequence suggests that recognition of homology precedes establishment of Watson-Crick base pairs in heteroduplex DNA. Dissociation 
of the complexes following deproteinization indicates that the bonds mediating identical strand recognition are weak. Nevertheless, these weak interactions are likely to be important in the search for homology.

The minimum length of homologous duplex that meets the size threshold for pairing is around $50 \mathrm{bp}$, or five turns of the helix. This is well above the minimum length necessary for maintenance of duplex conformation under the reaction conditions of temperature and ionic strength and is similar to the size threshold determined for pairing linear duplex and singlestranded circular molecules by RecA protein (10). In the case of RecA protein, the size threshold was found to be lower when pairing of single-stranded oligonucleotides and superhelical DNA was measured (13), but these conditions were not tested with REC2 protein. The mechanism necessitating the size threshold is not understood, but it seems likely to reflect the cumulative total of weak interactions that enables formation of a nascent paranemic joint. Reduction of the threshold length by including RNA residues in one strand of the duplex could indicate that the conformation of the hybrid duplex contributes favorably to the strength of these interactions and lowers the activation energy required for procession to the paranemic joint. The overall conformation of RNA-DNA hybrids is different from B-form DNA (27, 37). Solution studies of such hybrids have revealed that the DNA strand has neither B-form nor A-form structure and that the pucker of DNA sugar residues is no longer $\mathrm{C} 2^{\prime}$-endo (8). Analysis of crystal structures of RNA-DNA chimeric duplexes has indicated that three RNA residues and perhaps even a single residue in a decamer sequence can drive the conformational equilibrium away from B-form structure (7). RNA-DNA base pairs in the central part of chimeric duplexes contribute to unwinding and partial destacking. Such perturbation of the geometry might facilitate initiation and/or stabilization of pairing with a homologous third strand.

The apparently paradoxical observations reported earlier indicating the presence of homologous pairing activity in extracts from the rec 2 mutant but the absence in extracts from the rec1 mutant remain unexplained (15). Given the identity of $R E C 2$ as the structural gene encoding the homologous pairing activity and the identity of the $R E C 1$ gene as encoding an exonuclease (33), the earlier published results appear virtually opposite to expectations. We have not yet resolved these puzzling results but do have some further clues to understanding the contradictory meaning of the original findings. The lesion responsible for the rec2-1 mutation is a deletion that removes several hundred base pairs spanning the $5^{\prime}$ end of the $R E C 2$ open reading frame and promoter elements in the $5^{\prime}$ untranslated region (29). By Northern (RNA) analysis, an mRNA is still detected in the rec2-1 mutant, although it is 2.1 $\mathrm{kb}$ in length, compared with the 2.7-kb REC2 mRNA. Presumably a cryptic promoter or else a promoter from an adjacent transcription unit is utilized to drive expression of the truncated open reading frame. The deletion removes the $\mathrm{N}$ terminal portion of REC2 including the putative nuclear localization signal and chromatin binding domain, but if an alternative translational start site were utilized, a truncated REC2 polypeptide with certain biochemical activities might be produced. Thus, the rec $2-1$ mutant might be defective for in vivo functions but not in vitro functions, accounting for the residual renaturation activity reported to be present in the rec2-1 mutant. Immunoblot analysis should help in investigating this possibility.

The $3^{\prime}-5^{\prime}$ exonuclease encoded by the $R E C 1$ gene has an unusual activity, namely, the ability to hydrolyze phosphorothioate ester linkages in addition to the usual phosphodiester linkage (33). Using $3^{\prime}-{ }^{35} \mathrm{~S}$-labeled DNA as a substrate, we have been able to monitor specifically the REC1 encoded exonuclease activity during column chromatography of $U$. maydis extracts (unpublished observations). The activity partially copurifies with the homologous pairing activity through a phosphocellulose column, raising the possibility that the $R E C 1$ and $R E C 2$ gene products associate physically to some extent. It might be imagined that this putative association is disrupted if the $R E C 1$ gene product is altered by mutation. Consequently, this might result in altered chromatographic behavior of the $R E C 2$ gene product and thus its apparent absence from the expected column fractions. An alternative explanation that the $R E C 1$ gene might positively regulate expression of $R E C 2$ was ruled out by the finding of normal levels of the REC2 mRNA in the recl mutant.

In summary, there are three important findings in this report. First, the gene encoding the $U$. maydis homologous pairing protein known previously as rec1 has been identified as $R E C 2$. Second, the REC2 protein purified after overexpression of the gene in $E$. coli is active in promoting pairing of homologous DNA molecules in an ATP-dependent manner. Third, RNA-DNA hybrids are active in pairing under conditions in which DNA duplexes are not active.

\section{ACKNOWLEDGMENTS}

This work was supported in part by a grant from the Council for Tobacco Research, Inc., to E.B.K. and NIH grant GM42482 to W.K.H.

Thanks are due to W. Lane and V. Bailey, Harvard University, and G. Dubois, Thomas Jefferson University, for peptide fractionation and amino acid sequence analysis; to A. Andrus, Applied Biosystems, Inc., and F. Oakes, Apollon, Inc., for oligonucleotide synthesis; and to B. Rubin, Cornell University Medical College, for plasmid construction. We are grateful to Lorraine Symington for discussion and comments on the manuscript.

\section{REFERENCES}

1. Aboussekhra, A., R. Chanet, A. Adjiri, and F. Fabre. 1992. Semidominant suppressors of Srs2 helicase mutations of Saccharomyces cerevisiae map in the $R A D 51$ gene, whose sequence predicts a protein with similarities to procaryotic RecA proteins. Mol. Cell. Biol. 12:3224-3234.

2. Basile, G., M. Aker, and R. K. Mortimer. 1992. Nucleotide sequence and transcriptional regulation of the yeast recombinational repair gene $R A D 51$. Mol. Cell. Biol. 12:3235-3246.

3. Bauchwitz, R., and W. K. Holloman. 1990. Isolation of the REC2 gene controlling recombination in Ustilago maydis. Gene 96:285288.

4. Bianchi, M., C. DasGupta, and C. M. Radding. 1983. Synapsis and the formation of paranemic joints by $E$. coli RecA protein. Cell 34:931-939.

5. Bishop, D. K., D. Park, L. Xu, and N. Kleckner. 1992. DMC1: a meiosis-specific yeast homolog of $E$. coli recA required for recombination, synaptonemal complex formation, and cell cycle progression. Cell 69:439-456.

6. Campbell, J. L., C. C. Richardson, and F. W. Studier. 1978. Genetic recombination and complementation between bacteriophage T7 and cloned fragments of T7 DNA. Proc. Natl. Acad. Sci. USA 75:2276-2280.

7. Egli, M., N. Usman, and A. Rich. 1993. Conformational influence of the ribose 2'-hydroxyl group: crystal structures of DNA-RNA chimeric duplexes. Biochemistry 32:3221-3237.

8. Fedoroff, O. Y., M. Salazar, and B. R. Reid. 1993. Structure of a DNA:RNA hybrid duplex: why RNaseH does not cleave pure RNA. J. Mol. Biol. 233:509-523.

9. Fotheringham, S., and W. K. Holloman. 1991. Extrachromosomal recombination is deranged in the rec2 mutant of Ustilago maydis. Genetics 129:1053-1060.

10. Gonda, D. K., and C. M. Radding. 1983. By searching processively RecA protein pairs DNA molecules that share a limited stretch of homology. Cell 34:647-654. 
11. Heyer, W.-D. 1994. The search for the right partner: homologous pairing and DNA strand exchange proteins in eukaryotes. Experientia 50:223-233.

12. Holliday, R. 1967. Altered recombination frequencies in radiation sensitive strains of Ustilago. Mutat. Res. 4:275-288.

13. Hsieh, P., C. S. Camerini-Otero, and R. D. Camerini-Otero. 1992 The synapsis event in the homologous pairing of DNAs: RecA recognizes and pairs less than one helical repeat of DNA. Proc. Natl. Acad. Sci. USA 89:6492-6496.

14. Kans, J., and R. Mortimer. 1991. Nucleotide sequence of the RAD57 gene of Saccharomyces cerevisiae. Gene 105:139-140.

15. Kmiec, E., and W. K. Holloman. 1982. Homologous pairing of DNA molecules promoted by a protein from Ustilago. Cell 29:367374.

16. Kmiec, E., and W. K. Holloman. 1983. Heteroduplex formation and polarity during strand transfer promoted by Ustilago rec1 protein. Cell 33:857-864.

17. Kmiec, E., and W. K. Holloman. 1984. Synapsis promoted by Ustilago rec1 protein. Cell 36:593-598.

18. Kmiec, E., and W. K. Holloman. 1986. Homologous pairing of DNA molecules by Ustilago rec1 protein is promoted by sequences of Z-DNA. Cell 44:545-554.

19. Kmiec, E., and W. K. Holloman. 1994. ATP-dependent DNA renaturation and DNA-dependent ATPase reactions catalyzed by the Ustilago maydis homologous pairing protein. Eur. J. Biochem. 219:865-875.

20. Kmiec, E., and W. K. Holloman. 1994. DNA strand exchange in the absence of homologous pairing. J. Biol. Chem. 269:1016310168.

21. Kmiec, E., P. E. Kroeger, M. J. Brougham, and W. K. Holloman. 1983. Topological linkage of circular DNA molecules promoted by Ustilago rec1 protein and topoisomerase. Cell 34:919-929.

22. Kowalczykowski, S. C. 1991 . Biochemistry of genetic recombination: energetics and mechanism of DNA strand exchange. Annu. Rev. Biophys. Biophys. Chem. 20:539-375.

23. Kowalczykowski, S. C., and A. K. Eggleston. Homologous pairing and DNA strand exchange proteins. Annu. Rev. Biochem., in press.

24. Radding, C. M. 1989. Helical recA nucleoprotein filaments mediate homologous pairing and strand exchange. Biochim. Biophys. Acta 1008:131-145.

25. Radding, C. M. 1991. Helical interactions in homologous pairing and strand exchange driven by RecA protein. J. Biol. Chem. 166: 5355-5358.

26. Rao, B. J., and C. M. Radding. 1993. Homologous recognition promoted by RecA protein via non-Watson-Crick bonds between identical DNA strands. Proc. Natl. Acad. Sci. USA 90:6646-6650.

27. Roberts, R. W., and D. M. Crothers. 1992 . Stability and properties of double and triple helices: dramatic effects of RNA or DNA backbone composition. Science 258:1463-1466.

28. Roca, A. I., and M. M. Cox. 1991. The RecA protein: structure and function. Crit. Rev. Biochem. Mol. Biol. 25:415-456.

29. Rubin, B. R., D. O. Ferguson, and W. K. Holloman. 1994. Structure of $R E C 2$, a recombinational repair gene of Ustilago maydis, and its function in homologous recombination between plasmid and chromosomal sequences. Mol. Cell. Biol. 14:62876296.

30. Shinohara, A., H. Ogawa, and T. Ogawa. 1992. Rad51 protein involved in repair and recombination in S. cerevisiae is a recA-like protein. Cell 69:457-470.

31. Studier, F. W. 1991. Use of bacteriophage T7 lysozyme to improve an inducible T7 expression system. J. Mol. Biol. 219:37-44.

32. Studier, F. W., and B. A. Moffatt. 1986. Use of bacteriophage T7 RNA polymerase to direct selective high level expression of cloned genes. J. Mol. Biol. 189:113-130.

33. Thelen, M. P., K. Onel, and W. K. Holloman. 1994. The REC1 gene of Ustilago maydis involved in the cellular response to DNA damage encodes an exonuclease. J. Biol. Chem. 269:747-754.

34. Thomas, C. A. 1966. Recombination of DNA molecules. Prog. Nucleic Acids Res. Mol. Biol. 5:315-337.

35. van de Sande, J. H., K. Kleppe, and H. G. Khorana. 1973. Reversal of bacteriophage T4 induced polynucleotide kinase action. Biochemistry 12:5050-5055.

36. van Wezenbeek, P. M. G. F., T. J. M. Hulsebos, and J. G. G. Schoenmakers. 1980. Nucleotide sequence of the filamentous bacteriophage M13 DNA genome: comparison with phage fd. Gene 11:129-148.

37. Wang, A. H. J., S. Fujii, J. H. van Boom, G. van der Martel, S. A. A van Boeckel, and A. Rich. 1982. Molecular structure of r(GCG) d(TATACGC): a DNA-RNA hybrid helix joined to double helical DNA. Nature (London) 299:601-604.

38. West, S. C. 1992. Enzymes and molecular mechanisms of genetic recombination. Annu. Rev. Biochem. 61:603-640. 